\title{
The Information Literacy Model of Library Users in Supporting Tridharma
}

\author{
Malta Nelisa \\ The Study Program of Information, Library, and Archive \\ UniversitasNegeri Padang \\ Padang, Indonesia \\ malta@fbs.unp.ac.id
}

\author{
Ardoni \\ The Study Program of Information, Library, and Archive \\ UniversitasNegeri Padang \\ Padang, Indonesia \\ ardoniyonas@gmail.com
}

\begin{abstract}
This paper aims to explain the information literacy model of library users at UniversitasNegeri Padang (UNP) and UniversitasAndalas (Unand). The method used is qualitative descriptive through the review of the information literacy model which includes the starting, chaining, browsing, differentiating, monitoring, extracting, verifying, dan ending phases. The results show that the model used by students in both universities. In addition, alternative strategies are also generated in the information literacy those can be applied by students to maximize the existence of library information sources in order to support the implementation of the university tridharmasuch as education, research, and community service.
\end{abstract}

Keywords—information literacy; library users; academic libraries

\section{INTRODUCTION}

It is known that library carries out various activities of managing information sources in order to provide better services for its users. The existence of the library in university environment is as animportant tool in supporting the implementation of the universityTridharma, teaching, research, and community service. The availability of library collections in accordance with the needs of information users andthe availability of user-friendly information retrieval tools, can improve the library quality from the users' point of view. Such point of view then makes the library bea main place for academic community, especially students and lecturers in information searching. Moreover, information and communication technology allows people to access information wherever and whenever needed in this current era.

The university library vision and mission must be in line with the vision and mission of the university that support the implementation of the university Tridharma. Article 12 clause (1) of the Law Nr. 43/2007 about librarystates that the library collection is selected, processed, stored, served, and developed in accordance with the interests of the users with attention to the information and communication technology development. Furthermore, in article 24 clause (2) itis mentioned that the university library has a collection, both the number of titles and the number of the reference copies, that sufficient to support the implementation of teaching, research, and community service activities.

UniversitasNegeriPadang (UNP) and UniversitasAndalas (Unand) are two state universities under the Ministry of Research, Technology, and Higher Education located in West Sumatra Province. From the cluster of science, UNP carries out courses it was found that most of the student mostly come from the field of education, while Unandcarries out courses for the field of pure science and this difference is related to their library collection. The more information services provided by the library, the more variation of users' information retrieval strategies. This research is provide an overview of the use of the two libraries and it is hoped that libraries can develop sources of information that appropriate to the users' needs. In addition, the libraries may consider to add other information services for the library development and for improving its quality.

University is the place for scientific communication. In the concept of scientific communication, the development of a science will be faster if there is the transfer of knowledge through scientific publications. To support this, lecturers and students need the relevant and qualified sources of information so that they can develop the field of science as their object. In addition to the use of library information sources, the speed and the accuracy of information retrieval are considered by the users in accessing the information. The library needs to know aboutusers information needs to provide a convenient and useful information retrieval tools.

Application of the concept of information literacy as a whole can be seen in the library users in the academic library. To implement the university Tridharma, users make use of all library information sources that are considered relevant to users information needs. Meanwhile, the library provides a variety of information services to facilitate users to access information sources that have been processed. Information search facilities have an important role as a link between information sources and users. Reitz (2004: 356) states that information literacy is an ability to find the information needed and understand how the library management, know the sources of information available, and is the knowledge that is usually used technically in the search for information. 
Septiyantono (2016: 1.12) states that: (1) information literacy is a person's ability to find, discover, analyze, evaluate, and communicate information; (2) information literacy is supported by the role of libraries in introducing the term information literacy, helping to acquire the information literacy capabilities, and providing easy access to information; (3) the mastery of information technology is very easy for someone to have information literacy.

Association of College and Research Libraries (ACRL) (2000), formulated the information literacy competency standard for universities as follows. (1) the ability to determine the nature and scope of the required information with coverage: defining information needs, identifying the different types and formats of potential information sources, taking into account the costs and benefits of information retrieval required, and reevaluating the nature and scope of the information required. (2) the ability to access the information needed effectively and efficiently with the scope of: selecting the most appropriate information retrieval or retrieval method to find the information needed, establishing and implementing an effective search strategy, rediscovering information online or privately using method, change the search strategy if necessary, record and process information and resources. (3) Evaluate information and resources critically with coverage: summarize key ideas cited from collected information, issue and use initial criteria to evaluate information and resources, collect key ideas for building new concepts, comparing new knowledge with prior knowledge to determine its added value, contradiction, or other unique characteristics of information, determine whether new knowledge has an impact on the value system and determine ways to unify differences, validate the understanding and interpretation of information through discussions with other individuals, the beginning does need to be revised. (4) Use information to accomplish specific objectives with coverage: use new and prior information for planning and the creation of exceptional results or performance, effectively communicating results to others. (5) Understand the economic, legal and social aspects related to the use of information, which are: to understand the issues surrounding information and information technology, to follow the rules and ethics related to the use of information resources, and to respect the use of information resources in communicating product or perform.

In the use of information, there are two aspects to note: (1) ethics in using information and making it part of a work or writing, (2) ethics in presenting the identity of the source of information used (Rifai, 2014: 9.3). Information literacy directs the user of information to carry out the ethics.

Ellis, Cox, and Hall in Septiyantono (2016: 7.26) put forward an information literacy model focusing on information retrieval techniques. This model is described in the form of information seeking phases. (1) Starting is an initial introduction to references to find information to be investigated further using secondary information sources such as abstract, index, subject catalog, preview or synoptic article, as well as self-made notes on the topics of interest. (2) Chaining, at this stage the user activity is linking the literature list to the core reference. The way to do this is by searching or browsing the bibliography contained in the core reference or searching for other referrals based on the subject or author's name of the core reference being used. (3) Browsing, is an information seeking activity undertaken to identify potential sources of information on a field of interest, such as through research abstracts, journaling lists, library information sources or on display at exhibitions or seminars. (4) Differentiating, is an activity to distinguish information sources to filter information based on referral quality, for example through the topic of study or approach used. (5) Monitoring, is an activity to monitor developments that occur in the areas of interest through access to information sources on a regular basis. Sources of information used include articles in journals, scientific communication with peers or experts, or monitoring of published materials in book form. (6) Extracting, this stage is used when making a literature review by selecting information through journal, catalog, subject bibliography, abstract, and index. (7) Verifying, an activity of assessment of information, whether it has been appropriate and precisely with the desired. (8) Ending, is the final stage of information retrieval that coincides with the end of a research activity or answering the problem that users are discussing.

\section{METHOD}

This research is conducted by using the qualitative method. The sample type used is incidental sampling. In this case 143 samples from the librarian who utilizes the library of UNP and Unand. The research indicators were made using the information literacy model from Ellis, Cox, and Hall in Sugiyantono (2016: 7.27) which included: starting, chaining, browsing, differentiating, monitoring, extracting, verifying, and ending. This model actually is the steps in the information retrieval. A principal part of the information literacy in this model is to extract information according to understanding of the information seeker and its use according to the information needs.

\section{A. Finding}

\section{FINDINGAND DISCUSSION}

The research results are discussed in three parts, namely: (1) literacy model of information of UNP, (2) model of information literacy of Unand, (3) implementation strategy of information literacy in higher education. The information literacy model used is based on the model proposed by Ellis, Cox, and Hall in Septiyantono (2016: 7.26), namely: starting, chaining, browsing, differentiating, monitoring, extracting, verifying, and ending. Based on the data that has been obtained, the academic community of the two high perguan who fill the questionnaire of research in the library are all students. 


\section{B. Literacy Information Model of Users inthe Library of UNP}

Based on the interpretation of data behavior of UNP users in the application of information literacy, it can be explained as follows. In the early stages, most users get initial information about referrals or sources of information used from peers or lecturers. Usually this kind of reference is a note made by the users in accordance with the information obtained through the people around him. In addition, the earliest reference sources in the determination of the topic for the creation of lecture or research assignments are also derived from reading reviews or synopsis of articles, and information through abstract bundles and library catalogs. From the data of respondents, it is known that most of them are first semester students, so it can be assumed that they are to library in order to search information to complete lecture tasks. Respondents who are in the final semester, semester 7 and semester 9 numbered part of the respondents who are in the first semester, so it can be assumed also the topics being searched is also related to research activities to complete the final project such as thesis.

At the chaining stage, tracing further information in order to locate a referral source is to use the information contained in the core references list. The reader also looks for other references, but remains based on the author's name and the subject contained in the core reference. The second alternative used by the user is the tracing of information through the abstract of research or the table of contents of the journal. Use of this method can further broaden the scope of users information needs, because through abstracts of research and list of journal contents there is the possibility of finding information relevant to the topic in demand.

Information about references that have been obtained in the previous stage, then cultivated discovery by the user in the stage of browsing. The sources of information most commonly used as referrals are internet sources. The next frequently referenced sources are library books, periodicals such as newspapers and magazines, as well as reference sources such as dictionaries, directories or encyclopedias. Based on this it can be seen that most of the users use varied sources of information in the completion of academic tasks. Only a small percentage of users use a few references to support their academic activities.

The next stage is differentiating, which is the selection of information sources based on the quality of referrals. The quality in question is the identification of information sources that emphasize on subjects selected to further retrieve the desired information. Furthermore, monitoring activities through monitoring of developments that occur on the topic of interest. Most users do this by communicating with peers. Another way is to update the topic under review through a journal or scientific article. Another alternative that visitors do is to access the library catalog.

In the next stage, that is extracting, some users make essays from all sources of information that are considered relevant to the topic or problem being sought or desirable. However, some others only occasionally perform this stage. It is assumed that some direct users use information obtained in the writing of academic tasks. This stage is sometimes ignored by users, but this is an important stage where the author wrote back all the information that has been obtained to be developed according to his understanding and synchronized with the topic of problems to be solved. The application of this stage will seriously train and familiarize the reader to self-study and produce original scientific work, thereby reducing the practice of plagiarism.

The next step that is also very important to do is verifying, where the information seeker conduct checking or re-assessment of information that has been obtained. Most readers make sure the information they get is the way they want. Others only occasionally perform this stage. If this stage is not done, will result in the results of academic tasks that are less satisfactory in terms of quality. In addition, the bias is assumed that the librarian does not understand the tasks he or she has made. The final stage is the ending, which is the activity carried out simultaneously with the end of an activity.

In general it is known that most UNP users do the information literacy model as expressed by Ellis and some rarely perform the complete stage.

\section{Literacy Information Model of User in the Library of Unand}

Unand researchers who are involved in this research are mostly students of the third semester, after which the first semester and semester five. There are only a few students who are in the final semester of seven and nine. The research findings related to the information literacy model show the following.

In the first stage of the starting, there is a less conspicuous quantity of early reference aspects used to select the topic of academic tasks. The user uses information sources from peers or lecturers, reviews or synopsis of books and articles, as well as information on abstract bundles or index or library catalogs. Furthermore, at the chaining stage, most readers look for further referrals by referring to the bibliography of the core reference used and the name of the author or subject in the core reference. Not too many users search the information through abstracts of research or journal contents. This is assumed to be due to the tendency of the user to refer information sources in the form of textbooks and the lack of knowledge about the use of abstracts of research results as well as lists of journal contents.

At the browsing stage, most users choose to search information through internet sources. This source is considered the fastest answer questions or problems in student academic tasks because it can be accessed whenever and wherever during of users have information and communication technology devices, minimal mobile phone or smartphone. The sources of information used next are books and periodicals in libraries, as well as library reference sources. Sometimes the user also searches the information through the book exhibition. Overall it can be seen that Unand users also use various information sources in order to meet the information needs. 
Next is the differentiating stage, where information seekers distinguish referral sources based on quality. In this case, most users do this by selecting specific references from all the references that have been collected. However, there are also rarer readers who do this, so it is assumed they directly use the sources of information obtained without collecting all relevant sources. In this stage skills are needed in identifying sources of information from both the topic of study and the quality of the sources.

Application of the next literacy model of information at the monitoring stage, the average user periodically updates the latest information on the topic he or she is interested in. They communicate with colleagues or lecturers, update topics reviewed through journals or scientific articles, and through library catalogs.

At the extracting stage, enough users are doing the extraction of relevant information sources to be used in academic writing. However, not a few also who sometimes do this stage. Even quite a few also rarely rewrite the information that has been obtained with their own language.

The next stage for verifying, done by almost some users. Some others do not re-check the information obtained whether relevant to what is needed or not. The final stage, the ending is done simultaneously with the completion of the work of academic tasks. At this stage can be known whether or not the quality of the process of academic tasks.

\section{Discussion}

Based on the findings of the application of information literacy model at UNP and Unand, almost all respondents completed the stages in the model. However, not all stages are always implemented. In the implementation of the university Tridharma, update and development of information, as well as the originality of scientific papers is a matter of concern for improving the quality of science. Information literacy model can guide the academic community, especially students in producing quality scientific work.

First, the starting, all respondents completed this stage. The most widely used initial reference sources are peers, experts or lecturers. This shows that scientific communication orally or face-to-face is considered more effective in getting information quickly. The role of lecturer as a scientific facilitator is very important to direct and guide students to find sources of quality information. In addition, colleagues contribute to providing the relevant sources of information the librarian is looking for to answer the academic tasks that will be completed.

Actually, the library provides other sources of information as well. The sources are journal article, abstract, index, bibliography, and catalog those can be used by the users. Unfortunately, almost all of the users do not use it because they do not know that the sources are available in the library. In addition, the librarians do not inform the availability of the sources.It is not rarely, the librarians provide bibliographic data such as journal title in the OPAC (Online Public Access Catalog), but there is no article title. The other reason is that the users only focus on books as the information sources.

Second, chaining. Based on the interpretation of data, the second librarians are looking for more information through the bibliography found in the core references. In this phase there are two ways of tracking information, through a list of core reference libraries and through the use of author or subject names in the core references list. In the second way, information tracking is assisted by means of tracking information such as bibliographic means. These tools are often available not updated in libraries, so the libraries do not refer to these sources much. On the other hand, the reader is sometimes not aware of this facility in the library and does not know how to use it to help track information. Information for the development of university library collections can be done by referring to the bibliography of books often used by the user. The librarian can also recommend the desired books to the library so that the information resources in the library are up to date.

At this stage, search through research abstracts as well as journal contents in both university learners are not in high numbers. This is in line with the previous stages, where the use of abstracts of research results is not so significant. Sources of information such as this if available up to date can accelerate the development of a science such as the concept of scientific communication. Third, browsingfor the first source of information in information retrieval, both university selectors chose to use internet resources. In this study, it is not yet known whether the internet resources used by the user are a valid, clear, and accountable source of content. Observing the availability of information in internet sources, the user should be smart in choosing information much less for the benefit of writing scientific papers. The number of plagiarism cases is evidence of low information literacy among the civitasacademica. The next source that many referents referenced is books and library reference resources. Meanwhile, the quantity of references to periodicals such as newspapers and magazines is less than other sources. For some areas of social science, the use of this resource may be more numerous. Respondents of this research more come from the field of science than the field of social science.

Fourth, differentiating. Identification of information resources is done by all the second university librarians. In this stage, the selection of information sources relevant to the issues studied. In general, the user distinguishes the source of information based on the availability of the desired subject, including the depth of discussion on the desired topic. Another consideration is credibility, ie the extent to which the source of information can be trusted and the information updates.

Fifth, monitoring by monitoring the progress of the reviewed topics. Most librarians in both universities prefer to update information about the topic they are studying through communication with colleagues or experts in this case including lecturers. Formal relationship becomes the main choice because it can be used as a means of information exchange. Other sources of information used by users are journal and catalog. In scientific communication, information sources of periodic publications are 
suggested for monitoring information over other sources. This is related to the character of the source that is published periodically and can disseminate the latest information more quickly than the publication of a book. In addition, articles in journals are considered to be more accountable in terms of content because it is a concise form of research that has been implemented or an in-depth study using the sources of information about a topic.

Sixth, extracting. This stage requires the expertise of the user in extracting information from various sources. The results of this study indicate an insignificant quantity of activity at this stage. That is, even though more than half of the librarians perform this stage, but other users are pretty much not doing it. Drawing information from multiple sources requires the ability to read quickly and read comprehension. Among the many sources of information that have been collected, it may be partly containing information with the same intent. In addition, reading comprehension can be more effective in searching information and at the same time mapping the answers contained in these sources, so that the completion of an academic task in the form of lectures and final assignments such as thesis can be done efficiently.

Seventh, verifying that is characterized by the assessment of information that has been obtained. Ellis, Cox, and Hall in Sugiyantono (2016: 7.28) stated that based on his research, social science researchers did not perform this stage, unlike scientists in science who undertook this stage to ensure that errors in information were obtained. The results of research on UNP and Unand users indicate that users derived from the field of social science also perform this stage. Eighth, ending is by looking at the results of information search as a whole that simultaneously with the end of activity completion of academic tasks.

Information literacy stages are sometimes ignored by students is to formulate information needs, prioritize the use of information from Internet sources without clarifying the information and sources clearly. Setiawan (2017: 8) states the need for search strategies and technological skills to obtain the right source of information available on the internet and information literacy is the foundation for tracking information quickly and accurately. In addition, sometimes students do not extract or extract the information obtained using the sentence and understanding itself, so it is not known level of understanding of the information obtained.

\section{E. Implementation Strategy of Information Literacy in Higher Education}

Information literacy is now an important part of educational material. Based on the information literacy model of Ellis, Cox, and Hall in Sugiyantono (2016: 7.26) and adopting some information literacy standards by the Association of College and Research Libraries (ACRL) (2000), the application of literacy can be formulated as follows. (1) Identifying and communicating information needs (2) Identifying the various types and forms of potential information sources (3) Selecting and using the retrieval system with various methods (4) Quoting, recording and processing information and sources. Summarizing the main ideas cited from the information gathered (6) Synthesizing the main ideas for building new concepts (7) Communicating results effectively to others (8) Knowing the use of information resources in communicating information.

In line with the above information literacy standard, the strategy in applying information literacy in universities especially for students can be formulated as follows.

(1) Familiarize students to identify their information needs through the formulation of questions to answer academic tasks given.

(2) Introduce sources of information that can be used as a reference in the search for information both in terms of type and form. In terms of information types are primary, secondary, and tertiary information sources. In terms of form, such as: books, periodicals, electronic sources, and others. In this case keep in mind the sources of what information is owned by the university.

(3) Introduce the use of university retrieval systems, as well as a means of retrieving accessible information, such as: library online catalogs, bibliographic tools, or use of internet services to access online information resources.

(4) Assign information retrieval using multiple sources of information by including complete bibliographic information and ensuring the source of information can be traced, and assigning the recording of information quoted from the source.

(5) Familiarize students revisit the information that has been written using their own sentences, as well as to determine the level of understanding of the information that has been obtained.

(6) Directing students to think or bring up other ideas that are comparable with the information that has been disclosed.

(7) Providing means of conveying information on the formulation or ideas that have been produced in the form of two-way communication, both in the form of oral and written.

(8) Emphasizes the benefits of information obtained for themselves and their environment, both theoretically and practically.

This strategy can be used for life long learning and problem solving in various forms. The literacy capability of information that is always sharpened and used, can create a capable and productive generation of acting. In addition, it can also reduce the consumption of instant information that is not clear source. People who are information literate, know when information is needed and know how to use information effectively. 


\section{CONCLUSION AND RECOMMENDATION}

The practice of information literacy has been implemented by the user in the implementation of the Tridharma. But the implementation is not comprehensive and need to be given a deeper understanding of the concept of information literacy in order to provide maximum results in the acquisition and use of information. Literasi information can be a form of structured mindset that is useful in solving various problems in a smart and objective way. It is suggested to educators such as teachers and lecturers to include models of information literacy in learning activities. For library managers to maximize the utilization of their information sources and to fully inform the availability and use of such sources of information.

\section{References}

Association of College and Research Libraries (ACRL).(2000). Information Literacy Competency Standards for Higher Education.http://www.ala.org/acrl/sites/ala.org.acrl/files/content/standards/standards.pdf, September 14, 2017.

Reitz, J. M. (2011). Online Dictionary for Library and Information Science.http://www.abc-clio.com/ODLIS/searchODLIS.aspx, September 14, 2017.

Rifai, A. (2014). PenelusuranLiteratur. Tangerang Selatan: Universitas Terbuka.

Septiyantono, T. (2016).LiterasiInformasi. Tangerang Selatan: Universitas Terbuka.

Setiawan, V. (2017). Librarian Communication Strategy in the Implementation of Information Literacy (Case Study in University with Using and Exploiting E-resources. JurnalPenelitianKomunikasidanOpiniPublik, Vol. 21 (1), 15 - 29.

Undang-Undang No. 43 Tahun 2007 TentangPerpustakaan. (2007). RetrievedSeptember 14, 2017 from http://www.pnri.go.id/law/undang-undang-nomor-43-tahun-2007-tentang-perpustakaan/ 